
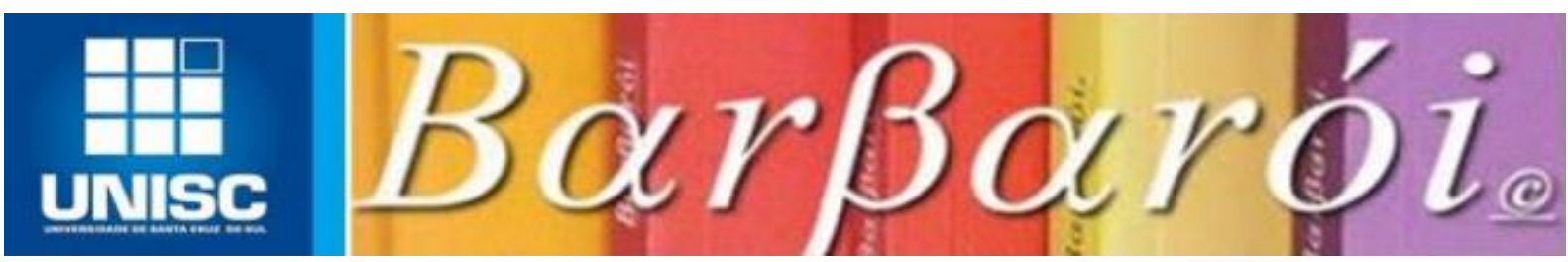

\title{
ASPECTOS HISTÓRICOS E EPISTEMOLÓGICOS SOBRE CRENÇAS DE AUTOEFICÁCIA: UMA REVISÃO DA LITERATURA
}

\author{
DOI: http://dx.doi.org/10.17058/barbaroi.v51i1.6391 \\ Tiago Fernandes Oliveira \\ Universidade Federal de Santa Catarina - UFSC - Brasil \\ Narbal Silva \\ Universidade Federal de Santa Catarina - UFSC - Brasil \\ Marúcia Patta Bardagi \\ Universidade Federal de Santa Catarina - UFSC - Brasil
}

\section{RESUMO}

Quando alguém se pergunta "Será que sou capaz de fazer?", está indagando sobre a crença que tem da sua autoeficácia, construto postulado por Albert Bandura em 1977, que se caracteriza pela percepção das pessoas acerca das próprias capacidades de organizar e executar cursos de ação requeridos para produzir certas realizações. No presente artigo consta um levantamento histórico dos antecedentes e da evolução do conceito da Teoria da Autoeficácia, sua relação com a Teoria Social Cognitiva, sua localização epistemológica, bem como uma investigação quantitativa de artigos publicados sobre autoeficácia nas bases de dados "Web of Science", "Scopus", "Biblioteca Brasileira de Dissertações e Teses", "Scielo" e "Lilacs/BVS". Foi possível associar a Teoria de Autoeficácia ao paradigma Interpretativista, o que direciona a compreensão das bases epistemológicas da teoria. $\mathrm{O}$ crescimento gradual da produção de artigos desde a década de 1970, em diversas áreas do conhecimento e não apenas em Psicologia, parece indicar a importância e amplitude científica do conceito, com destaque visível para as publicações estadunidenses.

Palavras-chave: Autoeficácia; Teoria Social Cognitiva; Pesquisa em Psicologia.

\section{INTRODUÇÃO}

Por que as pessoas se comportam de determinada maneira? Por que algumas pessoas conseguem desenvolver comportamentos que vão ao encontro dos seus objetivos e outras, mesmo com competências suficientes, não conseguem lograr êxito? Por que algumas pessoas desistem diante de dificuldades e outras perseveram? Por conta dessas inquietações, o comportamento humano ocupa o imaginário popular e é objeto de estudos acadêmicos que anseiam trazer maior compreensão sobre o tema. 
$\mathrm{O}$ início do séc. XX foi caracterizado como uma época revolucionária no que tange aos estudos sobre o comportamento - humano e animal -, com destaque para as publicações de Ivan Pavlov (1849-1936), John Watson (1878-1958) e Burrhus Skinner (1904-1990). Já na segunda metade do século passado, entre as décadas de 1950 e 1960 - conhecidas pela proeminência do movimento cognitivista/mentalista da Psicologia -, Albert Bandura iniciou seus estudos sobre a modelação social na motivação, pensamento e ação humana (BANDURA, 2006). Com o desenvolvimento e o amadurecimento das pesquisas na década seguinte, Bandura propôs o conceito de autoeficácia (BANDURA, 1977), o elemento que faltava para complementar sua teoria da aprendizagem social. Para o autor, as pessoas criam e desenvolvem percepções pessoais sobre si mesmas, e estas percepções se tornam instrumentos para alcançar os objetivos e auxiliar no controle que as pessoas exercem sobre o ambiente que as circundam (PAJARES; OLAZ, 2008).

Por meio da Teoria de Autoeficácia, Bandura quis demonstrar como as crenças pessoais afetam a motivação e a ação por meio da influência nos objetivos e nas aspirações que as pessoas apresentam. É com base nas crenças de autoeficácia que as pessoas escolhem quais desafios enfrentarão, o quanto de esforço despenderão no objetivo e por quanto tempo perseverarão diante de possíveis dificuldades (BANDURA, 1997). Quando as pessoas se perguntam "será que eu vou conseguir fazer?", estão questionando acerca das crenças de autoeficácia delas (VIEIRA; COIMBRA, 2006). Nessa perspectiva, elas se envolvem mais nas atividades que acreditam ser capazes de fazer e que esperam resultados positivos (NUNES; NORONHA, 2008).

A crença de autoeficácia se tornou, gradualmente, um constructo relevante no campo de investigação psicológica, visto que é numerosa a quantidade de trabalhos produzidos no cenário internacional e nacional - neste, em menor número -, em diversas áreas do conhecimento, como saúde, educação, trabalho e esporte (AZZI; POLYDORO, 2006; POLYDORO; AZZI; VIEIRA, 2010). Por exemplo, na pesquisa de Plotnikoff et. al. (2008), que avaliou um conjunto completo de determinantes para a realização de atividade física de pessoas com diabetes do tipo 1 e 2 , os resultados indicaram que a crença de autoeficácia foi a maior dos preditores de comportamento na população estudada, sinalizando a relevância empírica do conceito. Assim, as pesquisas e atualizações sobre crenças de autoeficácia em diversos contextos são relevantes para a sociedade em geral, pois ocupam um papel central nas estruturas causais do comportamento, afetando o funcionamento humano, tanto direta quanto indiretamente, impactando outras classes determinantes de conceitos orientados à 
ação, como as aspirações, os incentivos e desincentivos, as expectativas de resultados, as percepções de impedimentos e de oportunidades nas estruturas dos sistemas sociais, entre outros (BANDURA, 2009).

Os modelos racionais sobre motivação e tomada de decisão, nos quais as crenças de autoeficácia não são investigadas, acabam, por decorrência, não considerando uma significativa variável preditiva e explicativa. A crença de autoeficácia vai além de apenas levantar as opções para a ação, mas também regula a implementação das ações necessárias para atingir determinados objetivos. Pessoas podem decidir sobre um curso de ação, porém podem sentar e esperar passivamente que apareça o comportamento que as levarão ao objetivo. Contudo, decidir sobre algo não assegura que as pessoas desenvolverão e cumprirão as ações necessárias para atingir o objetivo, seja diante de dificuldades ou não (BANDURA, 2009). Nesse sentido, alunos com crenças de autoeficácia altas em relação à disciplina de matemática, por exemplo, insistirão em estudar um conteúdo difícil aos finais de semana, pois acreditam que, com esforço, poderão compreendê-lo e alcançar sucesso acadêmico na avaliação. Já os alunos com crenças de autoeficácia baixas em relação à mesma matéria, percebendo a dificuldade, e mesmo com as mesmas capacidades que os alunos exemplificados anteriormente, poderão protelar o início dos estudos, evitando o conteúdo e levantando desculpas para si mesmos e para outras pessoas, o que certamente dificultará o aprendizado e, por conseguinte, poderá implicar piores notas nas provas, confirmando as crenças anteriormente estabelecidas de que não alcançariam sucesso.

Considerando os argumentos até aqui expostos, no presente artigo de revisão da literatura, têm-se por objetivos: 1) descobrir os aspectos históricos, ontológicos, epistemológicos, de natureza humana e metodológicos referentes ao conceito de autoeficácia; 2) relacionar o conceito de autoeficácia com os pressupostos fundamentais da Teoria Social Cognitiva; e 3) investigar a quantidade de artigos, dissertações e teses publicados sobre crenças de autoeficácia desde sua criação formal em 1977 (BANDURA, 1977) até o ano de 2014, nas bases de dados nacionais e internacionais.

Na seção que se segue, procurar-se-á demonstrar os aspectos históricos fundamentais da Teoria da Autoeficácia, em especial, os seus precedentes, as evoluções do conceito e as interações estabelecidas com a Teoria Social Cognitiva. 


\section{Historicidade da Teoria da Autoeficácia: precedentes, evoluções e coexistência com a Teoria Social Cognitiva.}

Não há possibilidade de descrever e discutir a Teoria da Autoeficácia sem remeter ao nome de Albert Bandura. O nonagenário psicólogo canadense recebeu o título de doutor pela Universidade de Iowa em 1952 e, no ano seguinte, iniciou seus trabalhos na Universidade de Stanford, onde ainda leciona. Em artigo recente (DIENER; OISHI; PARK, 2014), Bandura foi identificado como o mais célebre psicólogo da era moderna (período compreendido como depois da Segunda Guerra Mundial), por suas contribuições teóricas, pelo impacto das citações de seus artigos e pelo recebimento de premiações científicas relevantes. Ainda, no final do ano de 2015, recebeu do presidente dos Estados Unidos a National Medal of Science, a maior premiação estadunidense para cientistas célebres (APA, 2016).

Suas primeiras pesquisas focalizaram o papel da modelação social na motivação, pensamento e ação humana. Naquela época, os psicólogos tendiam a focalizar os estudos de aprendizagem a partir das consequências das ações do próprio sujeito, em uma perspectiva behaviorista de explicação do comportamento, com a qual Bandura não concordava completamente (BANDURA, 2006).

Em 1963, Bandura e Walters publicaram o livro Social Learning and Personality Development, uma obra na qual se procurou responder às desilusões ainda da década de 1950 com a efetividade das técnicas psicanalíticas na terapia e com a capacidade das teorias psicodinâmicas de compreender a personalidade humana (BANDURA, 2006). Desse modo, a década de 1960 foi um momento crucial e propício para as mudanças paradigmáticas em relação à explicação e modificação do funcionamento humano (BANDURA, 2004). Ou seja, houve a migração de explicações inconscientes/psicodinâmicas para as explicações psicossociais, cuja ideia principal é a de que o comportamento humano é produto da interrelação dinâmica de aspectos pessoais, comportamentais e ambientais (BANDURA, 2006).

Os principais estudos que serviram de base para a formulação da Teoria da Autoeficácia foram produzidos na esfera clínica, precisamente em estudos para tratamento de fobias de cobras (BANDURA, 2006; POLYDORO; AZZI; VIEIRA, 2010). Na época, as pessoas que passaram pelo tratamento revelaram que as mudanças foram além da perda da fobia: a crença delas de autoeficácia foi transformada, de modo que, a partir de então, passaram a exercer um maior controle sobre as próprias vidas (BANDURA, 2006). E essa 
condição fez com que Bandura inclinasse sua pesquisa ao encontro da compreensão do fenômeno da autoeficácia.

Assim, em 1977, a Teoria da Autoeficácia foi publicada formalmente na revista Psychology Review por meio do artigo "Self-efficacy: Toward a Unifying Theory of Behavioral Change” (BANDURA, 1977). A teoria encontrava-se atrelada à outra teoria que Bandura (1976) denominou de Teoria da Aprendizagem Social. Bandura (1986a), posteriormente, renomeou-a de Teoria Social Cognitiva (BANDURA, 2006; POLYDORO; AZZI; VIEIRA, 2010). Embora possa ser investigada de forma independente, a Teoria da Autoeficácia terá maior consistência se for pautada pelo suporte teórico da Teoria Social Cognitiva, visto que elas mantêm elos teórico-explicativos (AZZI; POLYDORO, 2006).

A obra "Self-efficacy: the exercise of control" (BANDURA, 1997) foi um marco histórico na pesquisa em autoeficácia, pois foi nela que Bandura explicou as fontes de construção das crenças de autoeficácia, os processos de mediação envolvidos com essas crenças e o que estas afetam, além dos aspectos de interação com outros aportes teóricos da Teoria Social Cognitiva (POLYDORO; AZZI; VIEIRA, 2010). Para melhor entender as relações entre as duas teorias, Azzi e Polydoro (2006) realizaram um levantamento de quantas vezes os termos "Teoria Social Cognitiva" e "Teoria da Autoeficácia" aparecem no livro "Self-efficacy: the exercise of control". A frequência observada foi de 109 aparições destes termos, sendo 29 (26,6\%) delas para "Teoria de Autoeficácia" e $80(73,4 \%)$ para "Teoria Social Cognitiva". Em uma obra destinada à explicação da Teoria da Autoeficácia, esses números referentes às aparições do termo "Teoria Social Cognitiva" tornam evidente que "quando se fala em Teoria da Autoeficácia está se falando da Teoria Social Cognitiva" (AZZI; POLYDORO, 2006, p. 19).

$\mathrm{Na}$ Teoria Social Cognitiva (TSC) é apresentado um modelo explicativo para o funcionamento humano, que se diferencia de outras teorias propostas que focalizavam um modelo causal unidirecional (BANDURA; JOURDEN, 1991); no caso da TSC, a ideia é a de determinismo recíproco/triádico (BANDURA, 1986a). Nesse modelo, comportamentos, fatores pessoais e ambientais operam de modo interativo como determinantes que influenciam um ao outro bidirecionalmente (BANDURA; JOURDEN, 1991). A determinação comportamental é, então, probabilística - porquanto maior parte do comportamento é codeterminado por diversos fatores que operam interativamente (BANDURA, 1997). 


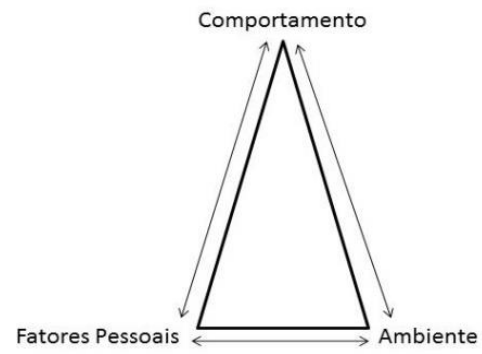

Fonte: Bandura (1997)

Por meio do modelo recíproco/triádico as pessoas são providas de oportunidades para exercer algum controle sobre suas vidas, assim como para impor limites ao seu direcionamento (BANDURA, 1997). Entendendo que o funcionamento humano é determinado por múltiplos aspectos de natureza ambiental, comportamental e pessoal, a crença de autoeficácia torna-se, desse modo, um mecanismo primordial da perspectiva de agência humana (AZZI; POLYDORO, 2006). Os seres humanos possuem um sistema de autorreferência, devido às capacidades básicas humanas de simbolizar, antecipar, de autorreflexão, de aprender de maneira vicária (com a ação de outros) e de se autorregular, o que os possibilita agir intencionalmente rumo a fins específicos, antecipar resultados, elaborar, replanejar e avaliar planos de ação (BANDURA, 2001; AZZI; POLYDORO, 2006).

A visão de ser humano para a Teoria Social Cognitiva é a de uma pessoa que se constitui por estar inserida nos sistemas sociais, sendo ao mesmo tempo agente e produto dessa relação, produzindo trocas e, por meio delas, adaptações e mudanças. O comportamento humano é expressão de uma relação interativa entre sujeito e ambiente. A relação recíproca/triádica, embora bidirecional (todos influenciam todos), não possui forças necessariamente equivalentes (AZZI; POLYDORO, 2006), ou seja, o ambiente, por exemplo, pode exercer mais forças influenciadoras no comportamento do que os fatores pessoais ou o próprio comportamento.

Conforme a concepção presente na Teoria Social Cognitiva, as crenças de autoeficácia mais facilitadoras do desenvolvimento de competências são aquelas que excedem ligeiramente o nível atual de competência que o ser humano tem (BANDURA, 1986; VIEIRA; COIMBRA, 2006). Em decorrência, o sujeito, nessas condições, poderá se envolver com a tarefa e se comprometer com os desafios que propiciarão o desenvolvimento de novas competências. Todavia, se as crenças de autoeficácia são superestimadas e/ou irrealistas se 
comparadas ao nível de competência que o sujeito possui, elas poderão ser desfuncionais e culminarem em fracasso da tarefa.

Quando as crenças de autoeficácia são pessimistas, ocorre a evitação de desafios acessíveis ao nível de competência do sujeito, o que inibe o desenvolvimento de novas possibilidades acadêmicas, profissionais, entre outras (LENT; BROWN; HACKETT, 1994; VIEIRA; COIMBRA, 2006). Já as crenças positivas de autoeficácia não irão compensar competências mínimas para o desempenho de determinada tarefa, elas não mais que facilitam o sucesso num domínio de desempenho determinado, desde que o ser humano possua níveis minimamente adequados de competências requeridas em uma atividade específica (LENT; HACKETT; BROWN, 1999; VIEIRA; COIMBRA, 2006).

É importante salientar que as escalas de autoeficácia não medem conhecimentos, habilidades e atitudes, mas o que as pessoas acreditam que podem fazer em determinadas circunstâncias, independentemente das competências que já possuam ou as competências que a tarefa requer (BANDURA, 1986b; POLYDORO; AZZI; VIEIRA, 2010). Estudos realizados em diferentes áreas do conhecimento indicam que a percepção de autoeficácia prediz melhor o comportamento subsequente do que as competências, pois a ação está mais relacionada às crenças do que ao que é objetivamente conhecido (BANDURA, 1997; AZZI; POLYDORO, 2006). Ou seja, a avaliação da autoeficácia é feita em relação à crença de possibilidade de lidar com os diversos aspectos envolvidos em determinada situação, e não apenas às subhabilidades envolvidas na tarefa (AZZI; POLYDORO, 2006). Em síntese, as crenças de autoeficácia ajudam a determinar as escolhas do ser humano relativamente aos meios de se chegar ao objetivo, assim como em relação ao esforço e à persistência quando confrontado com os obstáculos (VIEIRA; COIMBRA, 2006).

A partir do contexto referente aos preceitos da Teoria Social Cognitiva, discorrerar-seá sobre as diferentes conceituações que as crenças de autoeficácia tiveram ao longo de sua existência no meio acadêmico, as quais ocorreram por seis vezes (AZZI; POLYDORO, 2006). Estas mudanças representaram a evolução das delimitações e do amadurecimento das pesquisas e publicações na área. Em 1977, o conceito de autoeficácia era conhecido por “An efficacy expectation is the conviction that one can succesfully execute the behavior required to produce the outcomes" (1977, p. 193), o que poderia ser traduzido como "uma expectativa de eficácia é a convicção de que alguém pode executar com sucesso o comportamento requerido para produzir resultados". Já na obra "Self-Efficacy: the exercise of control" 
(BANDURA, 1997, p. 3), 20 anos depois da primeira conceitualização, Bandura definiu crença de autoeficácia como "Perceived self-efficacy refers to beliefs in one's capabilities to organize and execute the courses of action required to produce given attainments", ou “percepção de autoeficácia se refere às crenças de alguém em suas capacidades de organizar e executar cursos de ação requeridos para produzir certas realizações" (traduções nossas). Este é o conceito utilizado contemporaneamente.

Os pesquisadores Azzi e Polydoro (2006) fizeram comparações entre as evoluções conceituais da autoeficácia e observaram que, ao longo do tempo, foram evidenciados, nos conceitos elaborados por Bandura, dimensões da subjetividade humana, pelo uso dos termos “convicção", e, principalmente, por “julgamento" (BANDURA, 1982; 1984; 1986a) e “crenças" (BANDURA, 1995; 1997). Nesta concepção, o conceito de autoeficácia se encontra atrelado à ideia de convicção de realização com sucesso na execução de determinado comportamento na produção de resultados. Os conceitos de "julgamento" e de "crenças" estão relacionados à avaliação da capacidade pessoal na organização e execução de cursos de ação necessários para a produção de realizações. Outro ponto relevante a ser salientado nesse movimento das diferentes formulações é o reforço da ideia de agência humana na produção da própria trajetória, presentes nos termos "organizar" e "executar", relacionando essas ações a metas e objetivos (AZZI; POLYDORO, 2006).

O sistema de crenças de autoeficácia não é um traço global, mas um "conjunto diferenciado de crenças autorreferentes (self-beliefs) associadas a domínios distintos do funcionamento humano" (POLYDORO; AZZI; VIEIRA, 2010, p. 192). Medidas de autoeficácia gerais tenderiam a revelar um valor reduzido de predição e explicação (BANDURA, 1997). Ou seja, quanto maior for a especificação do que se deseja medir, maior será o poder de predição da ação. Há um foco de avaliação em um domínio específico da intenção e ação das pessoas, podendo haver percepções de elevada autoeficácia para determinadas atividades e baixa para outras (AZZI; POLYDORO, 2006). Por exemplo, poderse-ia medir o nível de crença de autoeficácia para o cuidado com a própria saúde, de modo geral, ou especificar mais, como a crença de autoeficácia para cuidado com a saúde coronária ou ortopédica.

Torna-se imperativo reiterar que crença de autoeficácia é diferente de intenção de realizar algo: aquela é um julgamento sobre a capacidade; esta é uma afirmação de intenção de efetivamente fazer algo, o que endereça para o conceito de atitude. Embora a autoeficácia 
percebida seja um dos principais determinantes da intenção, os dois construtos são conceitual e empiricamente diferentes (POLYDORO; AZZI; VIEIRA, 2010).

Quanto às formas de se desenvolver a autoeficácia, são quatro as principais fontes: experiência direta, experiência indireta (ou vicariante), persuasão social e por estados emocionais (BANDURA, 1997; BANDURA, 2009). O meio mais efetivo de propiciar uma forte autoeficácia é por meio das próprias experiências de sucesso (experiência direta com a tarefa). Contudo, se pessoas experienciam sucesso apenas por meio de resultados rápidos e fáceis, elas são facilmente desencorajadas a continuar a ação se por ventura falharem. Por conta disso, uma crença de eficácia resiliente requer superar obstáculos frente às dificuldades que inevitavelmente acontecem, pois, desse modo, aprende-se com os erros (BANDURA, 2009).

Outro meio de desenvolver a autoeficácia é pela modelação social, experienciando a ação de maneira indireta. Ao observar o esforço, a perseverança e o sucesso de outras pessoas com características e condições semelhantes, os seres humanos aumentam suas crenças de autoeficácia em suas próprias habilidades (BANDURA, 2009). Isto é, a aprendizagem vicária influencia mais quando o sujeito que executa com sucesso a ação está em condições similares de realizar a tarefa (por exemplo, um aluno observa outro aluno com similar capacidade cognitiva realizando um feito acadêmico) e não condições dissemelhantes (como um aluno que está em processo de aprendizagem observar um professor especialista em determinada área realizando a tarefa).

A terceira fonte é a persuasão social. Se as pessoas forem persuadidas a acreditar nelas mesmas, exercerão maior esforço na ação, e isso aumenta as chances de sucesso na consecução dos objetivos. Contudo, para que a influência seja efetiva, as pessoas que têm a função de persuadir devem ser conhecidas daqueles que necessitam da persuasão e praticar aquilo que pregam. Devem fazer mais do que aumentar a fé que as pessoas têm nelas, como organizar situações para os outros de modo a ajudar a alcançar os objetivos. Elas evitam colocar os aprendizes prematuramente em situações que eles poderão falhar. Os êxitos deverão ser medidos pelos ganhos progressivos, ao invés de serem comparados com o sucesso de outros. Em outras palavras, cada ser humano deve focar nos seus esforços, limites e possibilidades, não comparar êxitos, cujas situações e características são distintas (BANDURA, 2009). 
Por fim, a quarta fonte diz respeito aos aspectos emocionais e fisiológicos. As pessoas percebem tensões, ansiedades e cansaço como sinais de deficiência pessoal, afetando, assim, a própria percepção de eficácia. O humor positivo aumenta as crenças de autoeficácia; enquanto o humor negativo as diminui. Ao se reduzir a ansiedade e os sintomas depressivos e construir maior resistência e força física, as crenças de autoeficácia tendem a ser aumentadas (BANDURA, 2009).

Em síntese, as fontes de autoeficácia dificilmente operam de maneira independente, já que pessoas não só vivenciam resultados de experiências próprias, mas também observam outras pessoas em situações similares e recebem feedback sobre as ações realizadas. Desse modo, as influências se afetam entre si e podem mudar dependendo das forças de outras fontes de autoeficácia (NUNES; NORONHA, 2008). Considerando o que até aqui foi descrito e discutido, serão expostas, na seção a seguir, as diferentes perspectivas epistemólogicas que revestem o conceito de crenças de autoeficácia.

\section{Perspectivas ontológica, epistemológica, de natureza humana e metodológica da Teoria de Autoeficácia}

$\mathrm{Na}$ obra "Sociological Paradigms and Organizational Analysis: elements of the sociology of corporate life" (BURRELL; MORGAN, 2005), uma reedição da publicação original de 1979, os autores sistematizaram quatro paradigmas sociológicos: funcionalismo, interpretativismo, humanismo radical e estruturalismo radical. $\mathrm{O}$ funcionalismo e estruturalismo radical estão relacionados com a abordagem objetiva das ciências sociais; já o interpretativismo e o humanismo radical com a abordagem subjetiva (BURRELL; MORGAN, 2005). Nesse artigo, os postulados dos autores em relação a cada um dos paradigmas sociológicos serão brevemente descritos, para, em seguida, a Teoria de Autoeficácia ser classificada em um quadrante paradigmático condizente, de modo a contribuir para o entendimento epistemológico dela.

O interpretativismo e o funcionalismo, no que tange ao eixo da teoria de sociedade, encontram-se na perspectiva de regulação, que se refere a teorias preocupadas com a explicação dos fenômenos sociais por meio da coesão e da estabilidade. Já o estruturalismo radical e o humanismo radical referem-se a aspectos da teoria que versam sobre conflito e as mudanças sociais (BURRELL; MORGAN, 2005). Ou seja, o termo "radical", que complementa os constructos estruturalista e humanista, remete à ideia sociológica de 
necessidade de mudança do status quo. Já para a sociologia da regulação, a ordem, a integração e a atualidade são características fundamentais.

São quatro as pressuposições que norteiam os paradigmas sociológicos: as ontológicas, epistemológicas, de natureza humana e metodológicas. O pressuposto ontológico está ligado à essência do fenômeno investigado, que pode ser nominalista, quando o mundo externo à cognição humana é rotulado pelo sujeito que o observa; ou realista, quando independentemente da cognição do observador, há um mundo real, estruturado e tangível. O pressuposto epistemológico se refere ao modo como buscamos compreender o mundo, por meio de natureza positivista, por meio de explicações e predições racionais, regulares, buscando relações causais dos fenômenos; ou por meio do anti-positivismo, que é uma forma de compreender os fenômenos sociais levando em conta o caráter relativo, de que o ponto de vista dos sujeitos é fundamental para a compreensão do fenômeno social estudado. A natureza humana é o pressuposto que versa sobre a forma a qual se entende o ser humano em relação ao meio em que vive, seja em uma perspectiva determinista, que considera a ação humana determinada pelo ambiente que circunda o sujeito; ou pela perspectiva voluntarista, que versa sobre a autonomia do homem em relação ao meio, o que significa que o ser humano possui livre-arbítrio e é capaz de pensar e tomar decisões ainda que sob influência do meio. A natureza metodológica trata de uma consequência das perspectivas anteriores, pois estas auxiliam na construção de uma coerência metodológica para o andamento da investigação. Tem-se, nesse sentido, a perspectiva ideográfica, que se caracteriza pela abordagem de investigação que valoriza a compreensão que os sujeitos participantes fazem acerca do fenômeno em investigação; e a abordagem nomotética, valorizando o teste de hipóteses, técnicas rigorosas de investigação assim como as utilizadas nas ciências naturais (BURRELL; MORGAN, 2005).

Ao se considerar os aspectos paradigmáticos e epistemológicos levantados pelos autores, e pelo fato de a Teoria da Autoeficácia estar inserida na Teoria Social Cognitiva (BANDURA, 1986a), propõe-se a inserção daquela no paradigma interpretativista proposto por Burrell e Morgan (2005). O interpretativismo, localizado na perspectiva da regulação, caracteriza-se por tentar explicar os fenômenos sociais por meio de uma coesão e regularidade, em um âmbito subjetivo. As crenças de autoeficácia, indo ao encontro desta perspectiva, sugerem que o fenômeno seja pesquisado por meio da percepção dos sujeitos e de como essas percepções afetam o funcionamento humano. Assim, o pesquisador poderá 
compreender as regularidades deste funcionamento a partir do entendimento das crenças de autoeficácia.

No que se refere ao aspecto ontológico, as crenças de autoeficácia podem ser caracterizadas como nominalistas, tendo em vista que a realidade é construída a partir da cognição do sujeito. Isso significa que não se pode inserir as crenças de sujeitos como foco central de investigação sem entendê-las como estruturantes da realidade. Embora o ambiente influencie o comportamento, é a cognição humana que impulsiona a leitura deste ambiente e toma a decisão acerca do comportamento posterior.

Do ponto de vista epistemológico, embora Bandura tenha recebido influência do modelo positivista behaviorista - sendo rotulado, inclusive, como um neo-behaviorista -, a Teoria da Autoeficácia pode ser mais bem localizada em uma perspectiva anti-positivista. Pois, embora haja uma possibilidade significativa de predição e explicação do comportamento por meio do estudo das crenças de autoeficácia, é por meio da percepção dos sujeitos que se mede o fenômeno. Ou seja, as crenças de autoeficácia não são dimensionadas por meios tradicionalmente positivistas de observação do comportamento, livre de influências do pesquisador e demais subjetividades.

No que tange o entendimento de natureza humana, a Teoria da Autoeficácia está relacionada ao aspecto nominalista, já que a perspectiva da agência humana (BANDURA, 2001) é um dos conceitos-chave para a Teoria Social Cognitiva. A agência humana envolve fazer coisas de modo intencional, de maneira autorreflexiva, quando o sujeito pode moldar a própria vida por meio de suas ações devidamente planejadas, ainda que elas sofram influência de eventos fortuitos que inevitavelmente acontecem (BANDURA, 2008).

Para finalizar, o aspecto metodológico, que talvez seja entre os pressupostos o de fronteira mais tênue para localização das crenças de autoeficácia - ou o que pelo menos gera maior imprecisão, haja vista que, embora a avaliação das crenças de autoeficácia se destine a conhecer a percepção dos sujeitos, os instrumentos utilizados para a medição são objetivos, de rigor estatístico testado e que geram dados numéricos. Por conta dessas peculiaridades, aparentemente, a natureza metodológica das crenças de autoeficácia segundo as proposições de Burrell e Morgan (2005) são as mais delicadas de serem posicionadas dentro de um quadrante rígido nomotético ou ideográfico. É mais prudente afirmar que predominam métodos ideográficos, mas com influências nomotéticas consideráveis. 
$\mathrm{Na}$ seção posterior, será evidenciado o estado da arte das pesquisas nacionais e internacionais que tem como escopo a Teoria da Autoeficácia.

\section{O estado da arte das pesquisas em crenças de autoeficácia}

Para atingir os objetivos de levantar artigos científicos publicados em crenças de autoeficácia, pesquisou-se nas bases de dados "Web of Science", "Scopus", "Lilacs/BVS" e "Scielo"; para as dissertações e teses, na "Biblioteca Brasileira de Dissertações e Teses". Os termos pesquisados foram "Self-efficacy", "autoeficácia" e "auto-eficácia". Os critérios utilizados durante o levantamento de artigos foram: 1) os termos deveriam aparecer no título; 2) artigos, dissertações e teses publicados até o ano de 2014 ; 3) apenas artigos de revisão e empíricos. A partir destes critérios, levantou-se a quantidade de publicações nessas bases de dados, de modo a facilitar uma observação geral do estado da arte da pesquisa acadêmica sobre crenças de autoeficácia e bem como as evoluções quantitativas ao longo das décadas até os dias atuais.

$\mathrm{Na}$ base de dados "Scopus", foram encontrados 6.299 artigos empíricos ou revisões bibliográficas em que o termo "self-efficacy" aparece no título. A primeira publicação, conforme o esperado, é o artigo de Bandura (1977) em que o autor formalmente estabelece o conceito de autoeficácia. Pode-se observar um aumento gradual das publicações sobre esta temática nesta base: em 1994 foram publicados 50 artigos; no ano de 2004 foram 195 e, em 2014, 707 artigos. Entre 2010 e 2014, observou-se um incremento de 64,4\% no número de artigos publicados ao ano (de 430 para 707 artigos).

Gráfico 1: Artigos publicados na base "Scopus"” entre 1977 e 2014, cujos títulos continham o termo "selfefficacy”. A área indicada no gráfico expressa o crescimento das publicações.

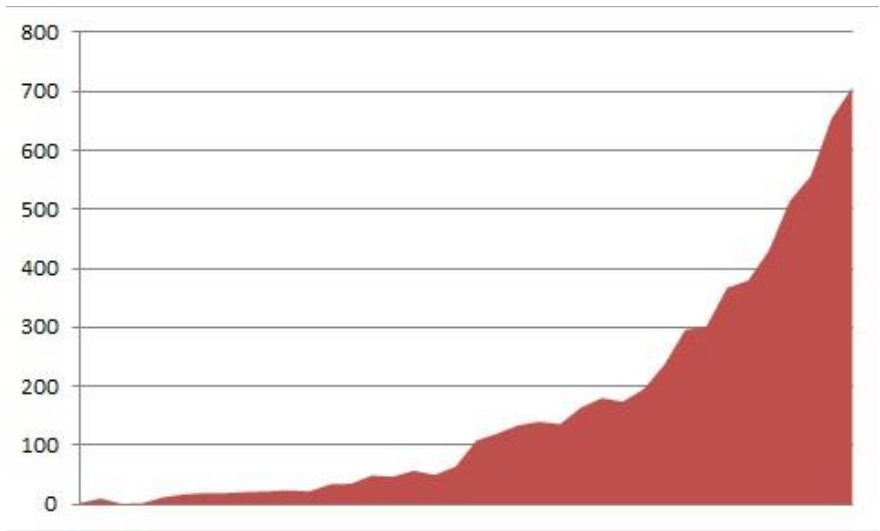

Fonte: pesquisa dos autores na base Scopus. 
Já na base de dados "Web of Science", foram encontrados 4.890 artigos. Assim como na base de dados "Scopus", o primeiro artigo incluído é o "Self-efficacy: Toward a unifying theory of behavioral change" (Bandura, 1977), que também é líder em citações com o termo "self-efficacy", com 11.028 citações, seguido de outro artigo de Bandura (1982), "Selfefficacy: mechanism in human agency", com 3.872 citações. Em relação ao número de publicações por ano, observamos também um aumento gradual: de 2005 a 2014 houve um incremento nas publicações anuais de 237,4\% (de 147 para 496 artigos); nos últimos cinco anos (2010-2014), as publicações passaram de 216 para 496 artigos ao ano. Segundo relatório da própria base "Web of Science", o país onde mais se publica são os Estados Unidos, com 2.601 publicações, ou 53,2\% do total; seguidos de Canadá (349 artigos ou 7,1\%), Austrália (309 artigos ou 6,3\%) e Inglaterra (269 artigos ou 5,5\%). O Brasil aparece na $27^{\mathrm{a}}$ posição com 31 artigos publicados $(0,63 \%)$.

Em relação à Biblioteca Brasileira de Dissertações e Teses, por meio do levantamento foi constatada a presença de oito teses e 17 dissertações com o termo de busca "autoeficácia". Já para o termo "auto-eficácia", com o uso do hífen, foram 12 teses e 29 dissertações disponíveis. Para o termo "Self-efficacy", foram encontrados 32 documentos ao todo, sendo 13 teses e 19 dissertações. Na base de dados "Scielo", foram encontrados 57 artigos cujo título continha os termos "auto-eficácia"; 157 artigos para "autoeficácia" e 144 artigos para "self-efficacy". Neste último descritor, os destaques sul-americanos em termos de publicação são o Brasil, com 57 artigos; Colômbia com 17; e Chile com 15. A limitação nessa base de dados se deu em virtude da impossibilidade de diferenciar os tipos de artigos (de revisão ou empíricos). Ao levarmos em conta o descritor em inglês "Self-efficacy", a revista "Formación Universitária" (Chile) é a que mais publica sobre a temática, com oito (8) artigos, seguida das revistas Psicologia: Reflexão e Crítica, Anales de Psicologia (Espanha), Psico-USF e Psicologia: Ciência e Profissão com cinco (5) artigos.

Por fim, na base Lilacs/BVS foram encontrados 292 artigos com o termo "autoeficácia", 105 com o termo "auto-eficácia" e 3.349 para "self-efficacy". Como se trata de uma base de dados com artigos em português, espanhol e inglês, muitos deles podem aparecer em todos os termos pesquisados, devido à tradução. Nos artigos em português nos quais o termo "autoeficácia" foi utilizado, o termo "auto-eficácia" aparece também nas traduções para o idioma espanhol. Em relação ao termo em inglês "self-efficacy", observa-se um aumento gradual nas publicações, ano a ano, com algumas exceções. Em 1994 o quantitativo de publicações foi de 29 artigos; 10 anos depois, em 2004, foram publicados 107 
artigos, e em 2014 o número de publicações chegou a 370 artigos. Nos últimos cinco anos (2010-2014), o número de publicações por ano cresceu 56,8\% (de 236 para 370 artigos), corroborando o crescimento observado nas outras bases de dados internacionais.

\section{Considerações Finais}

As crenças de autoeficácia ocupam um papel importante na estrutura causal do comportamento porque impactam em alguns determinantes deste, como as metas, as aspirações, as expectativas de resultado, os aspectos emocionais, a percepção de impedimentos ou de oportunidades. Também influenciam nos modos como as pessoas pensam - de forma otimista ou pessimista -, nos cursos de ação exigidos por determinadas tarefas, nos compromissos que têm com suas metas e ambições, nos esforços que colocam e no resultado que esperam desse investimento, na persistência diante de adversidades e de experiências malogradas, nos processos emocionais e fisiológicos que experimentam diante das demandas do ambiente e nas conquistas que conseguem alcançar (AZZI; POLYDORO, 2006; BANDURA, 2009).

Todos os aspectos influenciadores do comportamento supracitados indicam a substancialidade desta teoria, que ao longo de quatro décadas de existência tem suscitado estudos, de maneira crescente, em muitas áreas do conhecimento em que há indagação sobre como melhorar determinados aspectos motivacionais, como na aderência ao tratamento de certas doenças, como o HIV (JOHNSON et al, 2007) ou na aderência na prescrição nutricional para pacientes que realizam hemodiálise (ZRINYI et al, 2003).

De origem social-cognitivista, teoria elaborada e aperfeiçoada também por Bandura (1986a), a raiz da Teoria da Autoeficácia esteve atrelada ao amadurecimento da Psicologia Cognitiva, movimento que foi contemporâneo ao doutoramento de Bandura, bem como no amadurecimento das pesquisas deste autor. Ao observar que as pessoas que passaram pelo tratamento de fobia de cobras demonstravam maior confiança em outros aspectos das suas vidas, iniciou a inquietação sobre como o sistema de crenças da pessoa em relação às suas próprias capacidades influenciava nas ações desenvolvidas por elas rumo às suas metas e objetivos. Assim, a cognição humana adquiria cada vez mais presença nos estudos empíricos da Psicologia que até então eram dominados pelo Behaviorismo e pela perspectiva do comportamento observável pelo pesquisador. 
Podemos observar nas teorias de Bandura aspectos paradigmáticos interpretativistas, cujas características predominantes estão relacionadas à ontologia nominalista, à epistemologia anti-positivista, à natureza humana voluntarista e à metodologia ideográfica, encontrando-se na perspectiva da sociologia da regulação. Contudo, há de se considerar que o caráter meramente classificatório elaborado pelos autores deste artigo - bem como pela proposta de Burrell e Morgan (2005) - não pretende localizar de maneira estrita a Teoria da Autoeficácia ou a Teoria Social Cognitiva no quadrante interpretativista, pois, dependendo do ponto de vista do leitor, o cognitivismo social pode estar atrelado mais ao funcionalismo do que ao interpretativismo. Essas interpretações ficam evidenciadas principalmente quando o socio-cognitivismo se relaciona mais estreitamente com outras abordagens, como o Behaviorismo, como pode ser observado no artigo acerca dos paradigmas e eixos temáticos da Psicologia do Trabalho e Organizacional (PTO) no Brasil, de Bendassolli, Borges-Andrade e Malvezzi (2010). Os autores apresentam as categorias de paradigmas propostas por Guba (1990), relacionando-as com os eixos temáticos da PTO - a saber, o eixo do comportamento, o eixo da subjetividade e o eixo clínico. O Behaviorismo, o Neobehaviorismo e o Sociognitivismo encontram-se associados ao eixo do comportamento (Bandura influenciou direta e indiretamente, por meio de seus trabalhos, o segundo e o terceiro). Pela adoção, ao menos no Brasil, neste eixo temático, de pesquisas de campo (surveys) e correlacionais, que exigem operacionalização de construtos, mensuração e rigor no controle das variáveis (BENDASSOLLI; BORGES-ANDRADE; MALVEZZI, 2010), é possível que sejam feitas relações destes métodos com os métodos experimentais, que prezam pela (uni)causalidade, e, assim, podendo fomentar interpretações de que a Teoria Social Cognitiva estaria associada ao funcionalismo.

De fato, talvez as ciências cognitivas não figurem inflexivelmente em um quadrante paradigmático restrito, visto que a própria abordagem evoluiu de outro(s) paradigma(s), mantendo também características delas. É mais prudente citar que existe uma inclinação ou tendência epistemológica das teorias, ou que elas se encontram em uma trajetória ou movimento. Conhecer e compreender as origens epistemológicas as quais a pesquisa e prática psicológica estão relacionadas é substancial para que haja maior coerência dos trabalhos e métodos.

No que tange aos estudos empíricos e teóricos, é nítido o crescimento gradual, ano a ano, das publicações sobre crenças de autoeficácia, bem como o caráter internacionalizado delas. No Brasil, embora o quantitativo de publicações referentes à Teoria de Autoeficácia se 
destaque em relação aos outros países da América Latina, avanços quantitativos e qualitativos em relação às publicações são necessários, visto que estas se encontram muito limitadas a pesquisadores de determinados departamentos de algumas universidades (destacando-se a UNICAMP, Universidade São Francisco e Universidade Estadual de Londrina). Também se torna relevante o aumento de publicações de livros nacionais sobre a temática, haja vista que, pelo menos ao que está disponível nas maiores editoras e bibliotecas do país, há duas obras específicas sobre crenças de autoeficácia (AZZI; POLYDORO, 2006; AZZI; VIEIRA, 2014) e dois capítulos em outras obras (PAJARES; OLAZ, 2008; POLYDORO; AZZI; VIEIRA, 2010).

O objetivo principal deste artigo foi o de conhecer a historicidade e orientar o leitor acerca de aspectos ontológicos, epistemologicos, de natureza humana e de método que embasam o conceito de autoeficácia. Por conseguinte, identificamos como limitação a avaliação apenas quantitativa das publicações sobre autoeficácia, análise que pode apresentar riscos de superdimensionar números, em decorrência de possíveis estudos duplicados. Por conta disso, sugerimos futuros trabalhos que possam focalizar a realização de bibliometria sistemática do tema, cujos resultados indiquem aos leitores e pesquisadores, de maneira específica, as áreas em que as crenças de autoeficácia têm sido pesquisadas e em quais há maior necessidade de publicações para enriquecer o saber científico a respeito desse construto.

\title{
HISTORICAL AND EPISTEMOLOGICAL ASPECTS ABOUT SELF-EFFICACY BELIEFS: A LITERATURE REVIEW
}

\begin{abstract}
When someone asks oneself "Will I be able to do it?", he/she is inquiring about the beliefs that he/she has in his/her own self-efficacy, construct postulated by Albert Bandura in 1977, characterized by the people's perception about their own capabilites of organizing and executing courses of action required to produce certain achievements. In the present article contains a historical survey of antecedents and evolution of the concept of Self-efficacy Theory, its relationship with Social Cognitive Theory, its epistemological location, as a quantitative investigation of published articles about self-efficacy in the data bases "Web of Science", "Scopus", Biblioteca Brasileira de Dissertações e Teses", "Scielo", and "Lilacs/BVS". It was possible to associate Self-efficacy Theory to the Interpretivism paradigm, which directs the understanding of the epistemological basis of the theory. The gradual growth of the production of articles since the decade of 1970, in many areas of knowledge and not only in Psychology, seems to indicate the importance and scientific range of the concept, with emphasis in the United States of America publications.
\end{abstract}

Keywords: Self-efficacy; Social Cognitive Theory; Psychology research. 


\section{ASPECTOS HISTÓRICOS Y EPISTEMOLÓGICOS SOBRE CREENCIAS DE AUTOEFICACIA: UNA REVISIÓN DE LA LITERATURA}

\section{RESUMEN}

Cuando alguien se pregunta: "¿Soy capaz de hacer?" se pregunta sobre la creencia que tiene de su autoeficacia, constructo postulado por Albert Bandura en 1977, caracterizado por la percepción de las personas acerca de las propias capacidades para organizar y ejecutar cursos de acción necesarios para producir ciertos logros. En este artículo hay un estudio historico de los antecedentes y la evolución del concepto de la Teoría de la Auto-eficacia, su relación con la Teoría Social Cognitiva, su ubicación epistemológica, así como una investigación cuantitativa de artículos publicados sobre auto-eficacia en las bases de datos "Web of Science","Scopus","Biblioteca Brasileña de Tesis y Disertaciones","Scielo" y "Lilacs/BVS". Fue posible vincular la Teoría de la Auto-eficacia a paradigma Interpretativo, que dirige la comprensión de los fundamentos epistemológicos de la teoría. El crecimiento gradual de la producción de los artículos desde la década de 1970, en diversas áreas del conocimiento y no sólo en la psicología, indica la importancia y amplitud científica del concepto, con énfasis en publicaciones en los Estados Unidos.

Palabras-claves: Auto-eficacia; Teoría Social Cognitiva; Investigación en Psicología.

\section{REFERÊNCIAS}

APA - AMERICAN PSYCHOLOGICAL ASSOCIATION. Albert Bandura receives National Medal of Science. 2016. Disponível em: http://www.apa.org/monitor/2016/03/upfront-bandura.aspx Acesso em: 10 de Julho de 2018.

AZZI, R. G.; POLYDORO, S. A. J. Auto-eficácia proposta por Albert Bandura: algumas discussões. In: AZZI, R. G.; POLYDORO, S. A. J. (orgs). Auto-eficácia em diversos contextos. Campinas: Editora Alínea, 2006. pp. 9-24.

AZZI, R. G.; VIEIRA, D. A. Crenças de autoeficácia em contexto educativo. São Paulo: Casa do Psicólogo, 2012.

BANDURA, Albert. Self-efficacy: Toward a Unifying Theory of Behavioral Change. Psychological Review, v. 84, n. 2, p. 191-215, 1977.

BANDURA, Albert. Self-efficacy mechanism in human agency. American Psychologist, v. 37, n. 2, p. 122-147, 1982.

BANDURA, Albert. Recycling misconceptions of perceived self-efficacy. Cognitive therapy and Research, v. 8, p. 231-255, 1984. 
BANDURA, Albert. The explanatory and predictive scope of self-efficacy theory. Journal of Social and Clinical Psychology, v. 4, p. 359-373, 1986a.

BANDURA, Albert. The explanatory and predictive scope of self-efficacy theory. Journal of Clinical and Social Psychology, v. 4, p. 359-373, 1986b.

BANDURA, A.; JOURDEN, F. J. Mechanisms governing the impact of social comparison on complex decision making. Journal of Personality and Social Psychology, v. 60, n. 6, p. 941$951,1991$.

BANDURA, Albert. Exercise of personal and collective efficacy in changing societies. In: Press, 1995. pp. 1-45. (org.). Self-efficacy in changing societies. New York: Cambridge University

BANDURA, Albert. Self-efficacy: The exercise of control. New York: Freeman, 1997.

BANDURA, Albert. Swimming against the mainstream: the early years from chilly tributary to transformative mainstream. Behavioral Research and Therapy, v. 42, pp. 613-630, 2004.

BANDURA, Albert. Autobiography. In: LINDZEY, M. G.; RUNYAM, W. M. (orgs). A History of Psychology in autobiography. Washington: American Psychological Association, 2006. pp. 42-75.

BANDURA, Albert. Cultivate self-efficacy for personal and organizational behavior. In: LOCKE, E. A. (org.). Handbook of principles of organization behavior. 2 ed. 2009. pp. 179200.

BENDASSOLLI, P. F.; BORGES-ANDRADE, J. E.; MALVEZZI, S. Paradigmas, eixos temáticos e tensões na PTO no Brasil. Estudos em Psicologia, v. 15, n. 3, p. 281-189, 2010.

BURRELL, G.; MORGAN, G. Sociological Paradigms and Organisational Analysis: elements of sociology of corporate life. Aldershot: Ashgate, 2005.

DIENER, E.; OISHI, S.; PARK, J. An incomplete list of eminente psychologists of moderna era. Archives of Scientific Psychology, v. 2, p. 20-32, 2014.

GUBA, Egon Gotthold. The Paradigm Dialog. Londres: Sage, 1990. 
JOHNSON, M. O. et al. The role of self-efficacy in HIV treatment adherence: validation of the HIV Treatment Adherence Self-efficacy Scale (HIV-ASES). Journal of Behavioral Medicine, v. 30, n. 5, p. 359-370, 2007.

LENT, R. W.; BROWN, S. D.; HACKETT, G. Toward a unifying Social Cognitive Theory of Career and Academic Interest, Choice and Performance. Journal of Vocational Behavior, v. 45, n. 1, p. 79-122, 1994.

LENT, R. W.; HACKETT, G.; BROWN, S. D. A Social cognitive view of School-to-work transition. The Career Development Quartely, v. 47, p. 297-311, 1999.

NUNES, M. F. O.; NORONHA, A. P. P. Escala de auto-eficácia para atividades ocupacionais: construção e estudos exploratórios. Paidéia, v. 18, n. 39, p. 111-124, 2008.

PAJARES, F.; OLAZ, F. Teoria Social Cognitiva e autoeficácia: uma visão geral. In: BANDURA, A.; AZZI, R. G.; POLYDORO, S. Teoria Social Cognitiva: Conceitos Básicos. Porto Alegre: Artmed, 2008. pp. 97-114.

PLOTNIKOFF, R. C. et al. Physical activity and social cognitive theory: A test in a population sample of adults with type 1 and 2 diabetes. Applied Psychology, v. 57, n. 4, p. 628-643, 2008.

POLYDORO, S. A. J.; AZZI, R. G.; VIEIRA, D. Orientações de construção e aplicações de escalas na avaliação de crenças de autoeficácia. In: SANTOS, A. A. A. et al. (orgs). Perspectivas em Avaliação Psicológica. São Paulo: Casa do Psicólogo, 2010. pp. 189-210.

VIEIRA, D.; COIMBRA, J. L. A Auto-eficácia na transição para o trabalho. In: AZZI, R. G.; POLYDORO, S. A. J. (orgs). Auto-eficácia em diversos contextos. Campinas: Editora Alínea, 2006. pp. 25-58.

ZRINYI, M., et al. Dietary Self-efficacy: determinants of compliance behaviours and biochemical outcomes in haemodialysis patients. Nephorol. Dial. Transplant, v. 18, n. 9, p. 1869-1873, 2003.

\section{Sobre os autores}

Tiago Fernandes Oliveira é Psicólogo, especialista clínico em Psicologia Relacional Sistêmica e mestre em Psicologia pelo Programa de Pós-Graduação em Psicologia pela Universidade Federal de Santa Catarina, área Psicologia das Organizações e do Trabalho. Psicólogo do Instituto Federal Catarinense. Contato eletrônico: tiago.oliveira@ifc.edu.br 
Narbal Silva é Psicólogo, mestre em Administração, doutor em Engenharia de Produção e pós-doutor na área de Psicologia Positiva nas Organizações, no Trabalho e em outros Espaços da Vida. Professor Associado III do Departamento de Psicologia e docente do Programa de Pós-Graduação em Psicologia da Universidade Federal de Santa Catarina - UFSC. Contato eletrônico: narbal.silva@globo.com

Marúcia Patta Bardagi é Psicóloga, mestre e doutora em Psicologia, e pós-doutora na área de Aconselhamento Psicológico e de Carreira. Professora Adjunta II do Departamento de Psicologia e docente do Programa de Pós-Graduação em Psicologia da Universidade Federal de Santa Catarina - UFSC. Contato eletrônico: marucia.patta@ufsc.br 